DOI: 10.1016/j.forsciint.2012.06.017

\title{
FORENSIC SCIENCE INTERNATIONAL POST-PRINT
}

\section{Cyanide quantification in post-mortem biological matrices by headspace GC-MS}

\author{
Brigitte Desharnais $^{1,2}$ | Geneviève Huppé ${ }^{1}$ | Martine Lamarche ${ }^{1}$ | Pascal Mireault*1 | Cameron D. \\ Skinner ${ }^{2}$
}

${ }^{1}$ Department of Toxicology, Laboratoire de sciences judiciaires et de médecine légale, 1701 Parthenais Street, Montréal, Québec, Canada

${ }^{2}$ Department of Chemistry \& Biochemistry, Concordia University, 7141 Sherbrooke Street West, Montréal, Québec, Canada

\section{Correspondence}

*Pascal Mireault, 1701 Parthenais Street, Montréal, Québec, Canada, H2K 3S7.

Email: pascal.mireault@msp.gouv.qc.ca

\begin{abstract}
Cyanide is a powerful chemical asphyxiant found in some forensic cases following voluntary (suicide) or involuntary ingestion (fire, accidental exposure). A quantification method for cyanide that is specifically suited to post-mortem forensic purposes was developed. Determination was performed by headspace gas chromatography coupled to mass spectrometry using a GS-GASPRO column on an HP-6890 gas chromatograph with an HP-5973N mass detector. The biological sample was treated with an internal standard, frozen, glacial acetic acid was added and the sample was then incubated at $60{ }^{\circ} \mathrm{C}$ for $15 \mathrm{~min}$. The headspace was sampled with a disposable syringe, and analyzed to quantify hydrogen cyanide. Isotopically labeled cyanide $\left({ }^{13} \mathrm{C}^{15} \mathrm{~N}\right)$ was used as the internal standard to minimize matrix effect and sampling error. The method produced an extended linear dynamic range $(0.07-50 \mu \mathrm{g} / \mathrm{mL})$, and a method detection limit of $0.02 \mu \mathrm{g} / \mathrm{mL}$. Identical calibration curves were obtained when blood, gastric contents and aqueous solutions were used as the calibration standard matrix. This method was also successful in quantitating cyanide in gastric contents, one of the most variable biological fluids. The method has been validated and is being used for current forensic cases such as fire victims and suicides.

KEYWORDS:

Cyanide, gas chromatography, headspace analysis, blood, gastric content, forensic toxicology
\end{abstract}

\section{1 | INTRODUCTION}

Cyanide is a powerful toxic agent. It acts mainly as a chemical asphyxiant through fixation to cytochrome $\mathrm{C}$ oxidase, the mitochondrial enzyme responsible for the last step in cell respiration, and the blood oxygen transporter hemoglobin ${ }^{1,2,3}$.

Cyanide can be voluntarily ingested in suicides, usually in the form of a salt ( $\mathrm{KCN}, \mathrm{NaCN})$ but recently a suicide case by inhalation of $\mathrm{HCN}$ was also reported ${ }^{4}$. Cyanide exposure and absorption can also occur through inhalation of HCN produced in fires, or in cigarette smoke, due to the incomplete combustion of nitrogen products ${ }^{2}$. A synergistic effect is suspected between cyanide and carbon monoxide in fires ${ }^{5}$. Cyanide was reported to be responsible for a "knockout effect" in some fires, rendering the person unconscious well before carbon monoxide reached lethal levels. Finally, low levels of cyanide are generated in the body as a metabolite of nitroprusside, acetonitrile, acrylonitrile and cyanogenic glycosides ${ }^{6}$. 
The average endogenous level of cyanide in blood is $0.059 \mu \mathrm{g} / \mathrm{mL}$ for non-smokers and $0.123 \mu \mathrm{g} / \mathrm{mL}$ for smokers ${ }^{7}$. These value were compiled from multiple results by Baselt, but it should be noted that there is a large range of endogenous concentrations found depending on the study ${ }^{8}$. The blood concentrations found in suicide cases range from 1 to $53 \mu \mathrm{g} / \mathrm{mL}$ (average of $12.4 \mu \mathrm{g} / \mathrm{mL})^{7}$. In fire cases, the average blood concentration is reported to be $1.12 \mu \mathrm{g} / \mathrm{mL}^{7}$. There is no consensus on the precise toxic threshold for cyanide, but concentrations over $1 \mu \mathrm{g} / m L$ are generally considered toxic ${ }^{6}$.

Quantification of cyanide can be performed using various methods. Spectrophotometric assays have been used for a long time in forensic laboratories ${ }^{9,10,11}$. More recently, methods using HPLC $^{12,13,14,15}$ have been reported, but they typically require time consuming derivatization. Several GC methods have been demonstrated, either with ECD detection ${ }^{16}$, NPD detec$\operatorname{tion}^{17,18,19,20,21,22,23}$ or MS detection ${ }^{6,24}$. The headspace GC-MS method developed by Dumas et al. and Murphy et al. ${ }^{6,24}$ is very sensitive, fast and makes use of isotopically labeled cyanide as an internal standard. However, this method is not very well adapted for the postmortem forensic context because of its narrow linear dynamic range and limited applicability to non-traditional matrices.

In this paper the validation of a headspace GC-MS method of cyanide quantification specifically adapted for post-mortem toxicology is presented, as well as the results obtained for various forensic cases.

\section{2 | MATERIALS AND METHODS}

\section{1 | Reagents}

Sodium cyanide (reagent grade, 97\%) and sodium thiocyanate (trace metal basis, $\geq 99.9 \%$ ) were obtained from Sigma-Aldrich (St. Louis, MO, USA). Isotopically labeled potassium cyanide $\left(\mathrm{K}^{13} \mathrm{C}^{15} \mathrm{~N}\right)$ was purchased from Cambridge Isotope Laboratories $\left({ }^{13} \mathrm{C}: 99 \%\right.$ and ${ }^{15} \mathrm{~N}$ : $98 \%+$ Andover, MA, USA). Our analysis revealed that this reagent contains $\sim 0.4 \%$ of $\mathrm{K}^{12} \mathrm{C}^{14} \mathrm{~N}$. Sodium hydroxide was purchased from Anachemia (Montreal, QC, Canada). Ascorbic acid and glacial acetic acid were obtained from Fisher (Fair Lawn, NJ, USA). Bovine blood was obtained from MacDonald farm, McGill University (Ste-Anne-de-Bellevue, QC, Canada).

\section{2 | Analytical methods}

\subsection{1 | Sample preparation}

In a $20 \mathrm{~mL}$ headspace vial (LabSphere Inc., North Sutton, NH, USA), $1.0 \mathrm{~mL}$ of sample (unknown or spiked matrix) was mixed with $1.0 \mathrm{~mL}$ of deionised water and $0.25 \mathrm{~mL}$ of internal standard $\left(100 \mu \mathrm{g} / \mathrm{mL}{ }^{13} \mathrm{C}^{15} \mathrm{~N}^{-}\right.$in $\left.\mathrm{NaOH} 0.1 \mathrm{~N}\right)$. The sample was vortexed for $10 \mathrm{~s}$. A cap with an $8 \mathrm{~mm}$ center hole and $3.0 \mathrm{~mm}$ thick dark gray butyl septum was placed on the vial without crimping (Part 20031157, LabSphere Inc., North Sutton, NH, USA). The sample was then stored either for $2 \mathrm{~h}$ at $-20^{\circ} \mathrm{C}$, for $40 \mathrm{~min}$ at $-80^{\circ} \mathrm{C}$, or until it was frozen. Glacial acetic acid $(0.45 \mathrm{~mL})$ was then added to the sample and the vial quickly sealed by crimping the cap. The sample was then incubated in a Reacti-Therm ${ }^{\mathrm{TM}}$ heating/stirring module (Thermo, Rockford, IL, USA, model 18970) at $60^{\circ} \mathrm{C}$ for a minimum of $1 \mathrm{~min}$ in order for the blood to thaw and vortexed for $10 \mathrm{~s}$. After a minimum of $15 \mathrm{~min}$ of incubation the sample was vortexed again for $10 \mathrm{~s}$. Finally, $0.60 \mathrm{~mL}$ of the headspace was injected manually in the GC with a $1 \mathrm{~mL}$ 25G 5/8 disposable syringe (BD, Franklin Lakes, NJ, USA).

\subsection{2 । Headspace GC-MS analysis}

An HP-6890 GC coupled to an HP-5973 mass selective detector was used for the analysis. The separation was accomplished on an Agilent GS-GASPRO column (30 $\mathrm{m}$ length, $0.32 \mathrm{~mm}$ ID, $0.25 \mathrm{~mm}$ film thickness). Injections were made in the splitless mode. The injector was held at $150{ }^{\circ} \mathrm{C}$ and at a pressure of 5.7 psi. A GC Thermogreen ${ }^{\mathrm{TM}} \mathrm{LB}-211 \mathrm{~mm}$ septa (Supelco, St. Louis, MO, USA) and a gooseneck liner without glass wool (product 5183-4696, Agilent, Missisauga, ON, Canada) were used. The helium carrier gas (spec grade 5.0, BOC Gas, Montreal, QC, Canada) flow to the column was set to $2.3 \mathrm{~mL} / \mathrm{min}$. A purge step of $3 \mathrm{~min}$ was added, where a gas flow of $50.0 \mathrm{~mL} / \mathrm{min}$ went through the liner and to the vent in order to flush remaining products in the liner. The Gas Saver mode was turned off in order to allow more helium to run through the liner to displace any residual $\mathrm{HCN}$, hence reducing the carry-over. The initial oven temperature was $50^{\circ} \mathrm{C}$, and was ramped at a rate of $10^{\circ} \mathrm{C} / \mathrm{min}$ to $135^{\circ} \mathrm{C}$, and then 
at a rate of $60^{\circ} \mathrm{C} / \mathrm{min}$ to $230^{\circ} \mathrm{C}$ and held for $2 \mathrm{~min}$. The run time was $12.1 \mathrm{~min}$ with a solvent delay of $7 \mathrm{~min}$. The retention time of the analyte was $8.5 \mathrm{~min}$. The mass spectrometer was calibrated manually using the masses $18\left(\mathrm{H}_{2} \mathrm{O}\right), 28\left(\mathrm{~N}_{2}\right)$ and $32\left(\mathrm{O}_{2}\right)$ while the PFTBA was turned off. This procedure yielded better sensitivity for low masses. Chromatograms of ions $27\left(\mathrm{H}^{12} \mathrm{C}^{14} \mathrm{~N}^{+}\right)$ and $29\left(\mathrm{H}^{13} \mathrm{C}^{15} \mathrm{~N}^{+}\right)$were acquired using Selected Ion Monitoring (SIM) mode, with a dwell time of $350 \mathrm{~ms}$, which was selected after optimization. The MS source was held at $230^{\circ} \mathrm{C}$, the transfer line at $250^{\circ} \mathrm{C}$ and the MS quadrupole was held at $150{ }^{\circ} \mathrm{C}$.

\subsection{3 | Data analysis}

Data analysis was performed using Agilent MSD Chemstation, version E.02.01.1177. The ratio of integrated peaks (area of ion 27)/(area of ion 29) was used for quantification. Inverse weighing was used to build linear calibration models.

\section{3 | Experimental methods}

\subsection{1 | Linearity and accuracy}

Five calibrations, each of seven points $(0.00 ; 0.10 ; 0.40 ; 1.00 ; 5.00 ; 25.00$ and $50.00 \mu \mathrm{g} / \mathrm{mL}$ ), with two quality controls (QC; 0.50 and $15.00 \mu \mathrm{g} / \mathrm{mL}$ ) were prepared in bovine blood over a one month period. The slope and intercepts were compared to theoretical values, and the $R^{2}$ was used to evaluate linearity.

\subsection{2 | Reproducibility}

The reproducibility of the method was evaluated by analyzing three bovine blood samples doped with different concentrations $(0.75,7.50$ and $37.50 \mu \mathrm{g} / \mathrm{mL})$ in triplicate on three different days (nine measurements for each concentration) spread over 21 days. During this period, the system was opened for routine maintenance (column changed, MS vented) between the different sets of injections. To evaluate reproducibility, the \%RSD of the ratio of analyte area to internal standard area was used.

\subsection{3 | Limits of detection and quantification}

Eight blank injections of bovine blood were used in order to calculate $\sigma_{\text {blank }}$. These blank samples consisted of bovine blood not doped with cyanide but treated with internal standard.

\subsection{4 | Robustness}

To evaluate the robustness of the method, key parameters of the analytical procedure were modified and the system was calibrated, including QC samples as specified in Section 2.3.1. First, robustness toward the oven temperature was checked by changing the original temperature gradient to an isothermal program at $105^{\circ} \mathrm{C}$. Robustness toward the volume of headspace injected was tested by injecting $300 \mathrm{~mL}$ of headspace instead of $600 \mathrm{~mL}$. Finally, robustness toward the analyst was checked by having the method carried out by four previously untrained analysts.

\subsection{5 | Specificity toward thiocyanate}

To validate the method against thiocyanate interference, bovine blood samples containing either no cyanide or $0.50 \mu \mathrm{g} / \mathrm{mL}$ of cyanide were spiked at concentrations of $1 \mu \mathrm{g} / \mathrm{mL}$ and $12 \mu \mathrm{g} / \mathrm{mL}$ of thiocyanate, in order to reproduce the extremities of the endogenous concentration range. Cyanide in these four different samples was quantified in duplicate. It was possible that thiocyanate was already present in bovine blood, but the additions insured that the thiocyanate concentrations of the samples were at least $1 \mu \mathrm{g} / \mathrm{mL}$ and $12 \mu \mathrm{g} / \mathrm{mL}$.

The use of ascorbic acid to prevent the interconversion of thiocyanate to cyanide was tested. Ascorbic acid (100 $\mathrm{mg}$ ) was added to the samples before the acetic acid, as described in a published method ${ }^{6}$. Using this procedure, the method was calibrated and two samples (spiked with $12 \mu \mathrm{g} / \mathrm{mL}$ of thiocyanate) were quantified.

\subsubsection{Specificity toward decomposition products}

In order to make sure that no interference from decomposition products occurred, cardiac and femoral blood samples from victims with ages ranging from 17 to 70 years were analyzed. For this experiment, 17 victims in total were used, 13 males, 
4 females, 4 provided both cardiac and femoral blood, 7 provided cardiac blood and 6 provided femoral blood samples. About half of the victims were already decomposed or mummified when the cardiac or femoral blood samples were taken by the forensic pathologist. Cardiac blood samples were conserved in a plastic container and femoral blood samples were conserved in a BD Vacutainer tube with $100 \mathrm{mg}$ of sodium fluoride and $20 \mathrm{mg}$ of potassium oxalate. All samples were stored at $4{ }^{\circ} \mathrm{C}$. All of the samples originated from suspicious death victims but the cause of death was established and elevated levels of cyanide were not expected. Cyanide was quantified using a calibration curve as specified in Section 2.3.1.

\subsection{7 | Reduced sample volume}

The use of $0.25 \mathrm{~mL}$ or $0.50 \mathrm{~mL}$ of bovine blood sample for the analysis was validated. The reduced volume of sample was diluted to $1.00 \mathrm{~mL}$ with either bovine blood or water, and the normal procedure was then followed. Sample cyanide concentrations, before dilution, of 0.50 and $15.00 \mu \mathrm{g} / \mathrm{mL}$ were tested.

\subsection{8 | Matrices other than blood}

Three calibration curves of five points each $(0.0,0.1,1.0,5.0$ and $50.0 \mu \mathrm{g} / \mathrm{mL})$ were prepared in three different spiked matrices: bovine blood, gastric contents and water. Since gastric contents are highly variable, three gastric content samples from three cases, each with different consistencies and $\mathrm{pH}$ ranging from 5 to 7 were selected to evaluate the impact on the results. To allow quantitative aliquoting of the sample it was homogenized with a blender prior to cyanide addition.

\subsection{9 | Repeated injections from the same vial}

Successive injections (20) were made from bovine blood with a cyanide $0.10 \mu \mathrm{g} / \mathrm{mL}$ concentration. The headspace was sampled every $17 \mathrm{~min}$, the time required for the GC-MS to complete the chromatographic run and be ready for the next injection.

\subsubsection{0 | Stability of cyanide in blood}

Human blood stocks were spiked at two different concentrations $(0.50$ and $50.00 \mu \mathrm{g} / \mathrm{mL})$ and stored at $4{ }^{\circ} \mathrm{C}$ and $-20^{\circ} \mathrm{C}$ for a two week period. Samples were aliquoted before storage in order to avoid freeze-thaw cycles. Triplicate samples were then analyzed every day for fifteen days.

\subsubsection{1 | Analysis of forensic cases}

Cyanide in samples from forensic cases (poisoning or fires) were quantified. These biological samples were stored at the Laboratoire de Sciences Judiciaires et de Médecine Légale, which is the only mandated forensic laboratory in the province of Québec. According to the internal procedure, biological samples are stored for a period of 5 years following the production of a toxicology report, and are then destroyed. While the case is being analyzed, samples are stored at $4{ }^{\circ} \mathrm{C}$ in the same containers as specified in Section 2.3.6. When the case is closed, the samples are transferred to a freezer kept at $-20^{\circ} \mathrm{C}$. Cyanide was quantified using a calibration curve as specified in Section 2.3.1.

\section{3 | RESULTS AND DISCUSSION}

\section{1 | Chromatogram}

The developed method combines headspace analysis with a highly selective detector to yield a simple chromatogram (Figure 1 ) with a single peak. The analyte peak obtained exhibits a small amount of fronting, but produced plate numbers of 81500 , which compares favorably to the expected performance provided by the manufacturer (62400 theoretical plates).

\section{2 | Linearity and accuracy}

The average slope obtained was $0.0389( \pm 3.4 \%, n=5)$ and the average intercept $0.00509( \pm 6.2 \%)$ which compares favorably with the expected slope of 0.04 . Contamination of the internal standard (estimated at $1 \mu \mathrm{g}{ }^{12} \mathrm{C}^{14} \mathrm{~N} / \mathrm{dose}$ of IS) resulted in the 
FIGURE 1 Selected ion chromatograms obtained for (a) $\mathrm{m} / \mathrm{z} 27$ (HCN) for bovine blood samples of 0.1, 1.0 and $5.0 \mu \mathrm{g} / \mathrm{mL}$ and (b) $m / z 29\left(\mathrm{H}^{13} \mathrm{C}^{15} \mathrm{~N}\right)$ for a bovine blood sample $(0.1 \mu \mathrm{g} / \mathrm{mL})$.
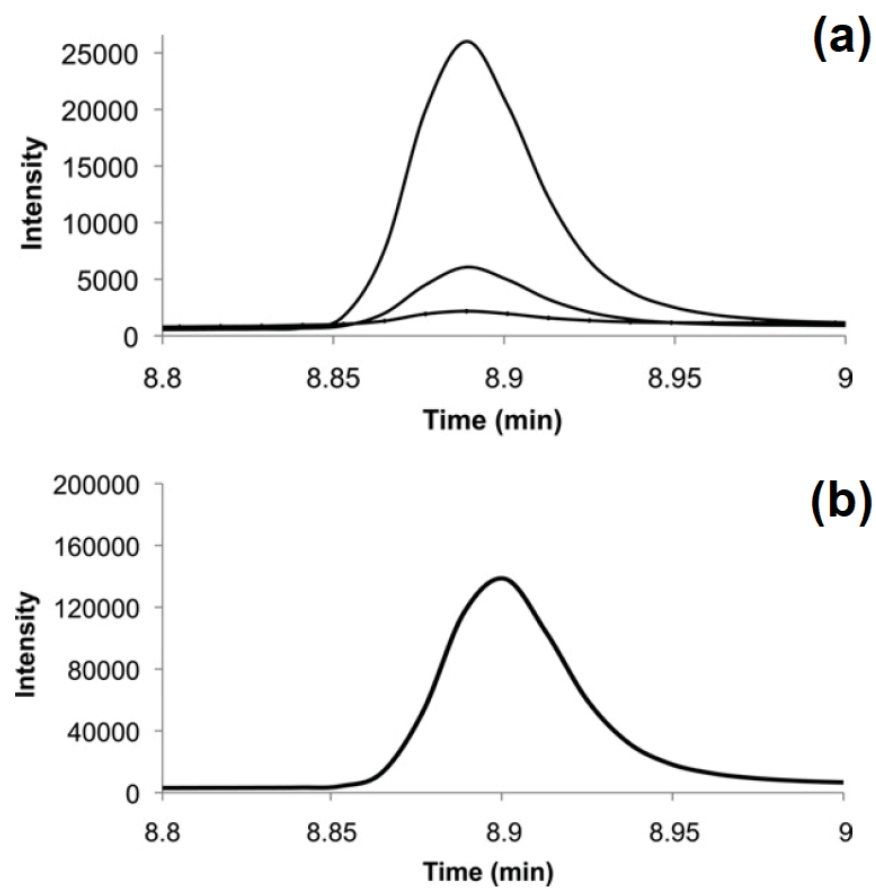

non-zero intercept, however, this was compensated for in the calibration. The endogenous $\mathrm{CN}$ in the bovine blood used for the standards introduced a negligibly small systematic error compared to the random error and can be discarded. All curves had $R^{2}>0.990$, which show a high degree of linearity even for the large dynamic range. The high linearity is further confirmed by the small standard error of the estimate, which is $4.3 \times 10^{-3} \mu \mathrm{g} / \mathrm{mL}$. The QC samples showed an average accuracy of $109.9 \%$ at $0.50 \mu \mathrm{g} / \mathrm{mL}$ and $108.4 \%$ at $15.00 \mu \mathrm{g} / \mathrm{mL}$ concentrations $(n=5)$. These results show the high accuracy of the method.

\section{3 | Reproducibility}

The intra-day relative standard deviation ranged from $1.8 \%$ to $2.6 \%$ and the inter-day $\%$ RSD ranged from $2.1 \%$ to $4.8 \%$ which is satisfactory. This shows that the internal standard corrects adequately for variations due to manual injection.

\section{4 $\mid$ Limits of detection and quantification}

The calculated $3 \sigma_{\text {blank }}$ LOD was $0.02 \mu \mathrm{g} / \mathrm{mL}$ and the $10 \sigma_{\text {blank }}$ LOQ was $0.07 \mu \mathrm{g} / \mathrm{mL}$. Other published methods have lower LOD, but this is most likely attributable to automation ${ }^{1,24}$. In any event, the LOQ obtained allows quantification at endogenous levels and quantification at lower levels would not serve any useful forensic purpose.

\section{5 | Robustness}

The method proved to be robust with respect to the oven temperature and the volume of headspace injected ( $300 \mu L$ injected yielded deviations from the expected concentrations under 10\%). The QC samples quantified by three different analysts all fell within the expected range with deviations under $10 \%$. The only training these analysts received was to watch the method being performed once. Therefore, this method does not require extensive training and is robust toward inter-analyst variation. 


\section{6 | Specificity}

\subsection{1 | Toward thiocyanate}

Artifactual formation of cyanide from thiocyanate has been reported to occur in the presence of oxyhemoglobin in an acidic environment ${ }^{25}$. Therefore there is a reasonable concern that this may happen during blood sample acidification and heating steps of this method. Thiocyanate is a metabolite of cyanide produced by the enzyme rhodanese, using thiosulfate as a substrate $^{2}$. Endogenous concentrations of thiocyanate in blood range from 1 to $12 \mu \mathrm{g} / \mathrm{mL}^{7}$. Based on the work of Seto et al., several published methods ${ }^{1,6,23,26}$ recommend the use of ascorbic acid to prevent thiocyanate interference.

The cyanide concentrations found in blood samples spiked with thiocyanate ( 1 and $12 \mu \mathrm{g} / \mathrm{mL}$ ) were, on average, increased by $0.04 \mu \mathrm{g} / \mathrm{mL}$ and $0.13 \mu \mathrm{g} / \mathrm{mL}$, respectively. These results suggest that there is a systematic error in the calculated cyanide concentration due to presence of thiocyanate in blood.

Given these results, addition of ascorbic acid to prevent thiocyanate interference was attempted. The use of ascorbic acid led to an average decrease of $9.6 \%$ peak area in the mass spectrometer. This phenomenon has already been reported by Murphy et al. ${ }^{24}$. Moreover, the samples still yielded a cyanide concentration that was on average $0.13 \mu \mathrm{g} / \mathrm{mL}$ above the expected concentration. Therefore it remains unproven that the use of ascorbic acid prevents thiocyanate interference.

Consequently, analysts have to be aware that thiocyanate interference is a possibility. However, even at the highest reported endogenous concentrations of thiocyanate, the interference is not likely to change the interpretation of the blood cyanide concentration by the forensic toxicologist. That is, it is improbable that a case would be falsely interpreted as being cyanide intoxication due to the thiocyanate. Future work should concentrate on characterizing more precisely the mechanisms of this interference and removing it.

\subsection{2 | Decomposition products}

Published methods using isotopically labeled cyanide as an internal standard have been validated for aqueous solutions and well-preserved (clinical) blood ${ }^{6,24}$, not for post-mortem samples. Forensic blood samples are characterized by the presence of decomposition products and are often partially or fully hemolyzed. The developed analytical strategy minimizes the complexity of the biological matrix by using a highly selective detector producing a chromatogram with a single peak. However, decomposition products are often volatile and could very well be sampled with the headspace.

All samples analyzed were found to have cyanide concentrations below the LOQ of the method, except 2 samples: a concentration of $0.10 \mu \mathrm{g} / \mathrm{mL}$ was found in one cardiac blood sample and a concentration of $0.08 \mu \mathrm{g} / \mathrm{mL}$ was found in one femoral blood sample. However, in both of these cases, the concentrations found were below the endogenous level expected for cyanide in smoker's blood. These results suggest that interference from the decomposition products would not produce erroneously high measurements with this method.

\section{7 | Reduced sample volume}

In forensic toxicology, it is common to have limited sample volume, especially if multiple analyses must be performed. This is particularly true in fire cases where the pathologist is often able to collect only a few milliliters of femoral blood for all analyses. In these situations, using one milliliter of sample for the cyanide analysis might not be practical or even possible.

Previously published methods usually require either $0.5 m L^{1,23,24,27}$ or $1.0 m L^{6,28}$ of blood sample. Only Frison et al. ${ }^{29}$ went below this volume and used $0.4 \mathrm{~mL}$ of blood.

Spiked samples at $0.50 \mu \mathrm{g} / \mathrm{mL}$ and $15.00 \mu \mathrm{g} / \mathrm{mL}$ (in the original sample) showed less than $10 \%$ deviation from the expected value $(90 \%<$ accuracy < $110 \%)$, whatever the initial volume or the diluant $(0.25 \mathrm{~mL}$ or $0.50 \mathrm{~mL}$, water or blood). This demonstrates that the original matrix is not affected by dilution. Therefore, a smaller volume of original sample can be used for the analysis. Caution must be exercised in interpreting the detection and quantification limits when diluted samples are used as these analytical figures would likely scale with the dilution factor. 


\section{8 | Matrices other than blood}

Quantification of cyanide in matrices other than blood might be needed in a forensic context. In the event where cyanide is ingested (solids or in a drink), establishing the cyanide concentration of the gastric contents might prove useful, for example to determine route of administration. To the best of our knowledge, no published method has been validated for quantification in gastric contents. This matrix is an analytical challenge because of its extreme variability. Since gastric content is an acidic matrix, some cyanide is expected to escape in the form of gaseous hydrocyanic acid. However, when people are exposed to massive doses of cyanide, an equilibrium process occurs, and if gastric contents are kept in a somewhat closed (stomach) or completely closed (plastic container) environment, a good part of the cyanide will be retained. Quantification of cyanide in aqueous solutions might also be required to analyze solutions (poisons) found at crime scenes.

Results of calibration showed excellent linearity $\left(R^{2}>0.990\right.$ and small standard error of the estimate) and similarity of the intercept and slope for all matrices as summarized in Table 1 . Considering these results, cyanide was quantified in water and gastric contents using spiked bovine blood for calibration since bovine blood would be the normal calibration matrix. For quantification at very low cyanide concentration, a calibration curve in water could be more accurate since it removes the systematic error stemming from the presence of endogenous cyanide in bovine blood. However, for more elevated concentrations such as those encountered in the forensic context, this small systematic error has no impact on the interpretation. Water samples showed accurate quantification throughout the linearity range. For gastric contents, results showed a deviation of $\pm 30 \%(n=3)$ from the expected value at the $0.50 \mu \mathrm{g} / \mathrm{mL}$ level. At the $1.00 \mu \mathrm{g} / \mathrm{mL}$ level and above, the precision improved to a maximum deviation of $\pm 15 \%(n=3)$ from the expected value. Since the minimal toxic dose for ingestion is considered to be $100 \mathrm{mg}^{7}$ which is likely to produce concentrations well in excess of $1.00 \mu \mathrm{g} / \mathrm{mL}$ in the gastric contents, this quantification threshold is acceptable.

TABLE 1 Calibration parameters for bovine blood, water and different gastric contents. A linear fit with $1 / x$ weighing was used.

\begin{tabular}{llll}
\hline Matrix & Slope $(m)$ & Intercept $(b)$ & $R^{2}$ \\
\hline Bovine blood & 0.03980 & 0.005 & 0.9990 \\
Water & 0.03926 & 0.005 & 0.9985 \\
Gastric content 1 & 0.03850 & 0.006 & 0.9998 \\
Gastric content 2 & 0.03795 & 0.009 & 0.9996 \\
Gastric content 3 & 0.03784 & 0.008 & 0.9996 \\
\hline
\end{tabular}

These results suggest that cyanide can be quantified in diverse matrices using a single calibration curve with the potential to save considerable analysis time and avoid the complications of preparing matrix-matched standards. However, quantification in gastric contents can only be considered accurate (error of $\pm 15 \%$ ) for concentrations of $1.00 \mu \mathrm{g} / \mathrm{mL}$ and above.

\subsection{Repeated injections from the same vial}

Confidence in quantification results can be improved from replicate analyses, since the confidence interval is proportional to the inverse square root of the number of measurements. However, the small volumes of forensic samples sometimes render independent replicate analysis difficult. A partial solution to improving the precision is to inject replicates from the headspace of the same vial. This strategy can improve the precision of the measurement process but cannot address sample preparation error. Theoretically, if sampling the headspace does not alter the sample concentration significantly and if enough time is given for equilibrium to be re-established between samplings, then the replicates should yield the same result. However, this is a disputed procedure, and its application to a method requires validation ${ }^{30}$. Only Murphy et al. ${ }^{24}$ used multiple sampling of the headspace for cyanide quantification, with $n=2$.

The results showed that at least twenty injections could be done from the same vial without the results exceeding the $15 \%$ error cutoff (Figure 2 ). These results suggest that the precision of the measurement can be improved, in an unbiased way, even when very little sample is available, but it cannot compensate for sample preparation errors. 
FIGURE 2 Results of successive injections of the headspace of a $0.01 \mu \mathrm{g} / \mathrm{mL}$ bovine blood sample.

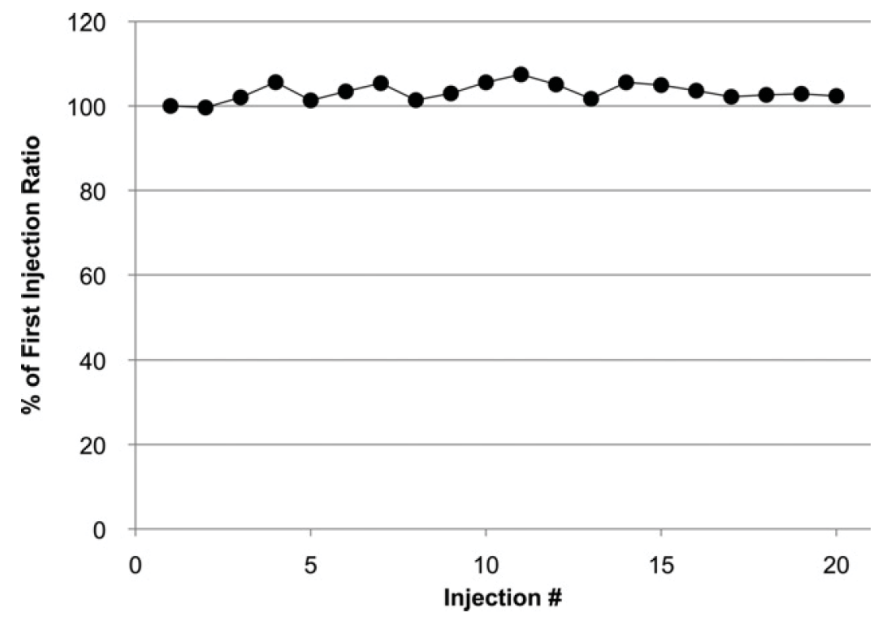

\subsection{0 | Stability of cyanide in blood}

The time-course behavior of cyanide concentration needs to be known in order for the forensic toxicologist to account for the delay between the time of death and the time of analysis and properly interpret the cyanide concentration. This poses a certain problem as the stability of cyanide in blood is a controversial topic with dramatically divergent literature. The concentration of cyanide in blood has been found to increase ${ }^{31}$, stay stable ${ }^{32}$ or decrease ${ }^{1,33}$ when the samples were stored at $4{ }^{\circ} \mathrm{C}$. For samples stored at $-20^{\circ} \mathrm{C}$, concentration either increased ${ }^{31}$ or stayed stable ${ }^{33}$. None of these studies were performed with a GC-MS method and often have a lower sensitivity or accuracy. Since the literature is contradictory, an experiment to test stability of cyanide in human blood was done.

Figure 3 illustrates that no clear trend was observed: neither a systematic increase nor a decrease of the concentration. A certain amount of variation is present, with a maximum value of $117 \%$ and a minimum value of $86 \%$. The error, calculated over the triplicate analysis, varies between $24 \%$ and $0.3 \%$, with an average of $5 \%$.

FIGURE 3 Percent of day 1 area counts for cyanide in human blood samples at a concentration of $0.50 \mu \mathrm{g} / \mathrm{mL}$, over a two week period at storage temperatures of $4{ }^{\circ} \mathrm{C}(\bullet)$ and $-20^{\circ} \mathrm{C}(\circ)$ and at a concentration of $50.00 \mu \mathrm{g} / \mathrm{mL}$, over a two week period at storage temperatures of $4{ }^{\circ} \mathrm{C}(\square)$ and $-20^{\circ} \mathrm{C}(\square)$.

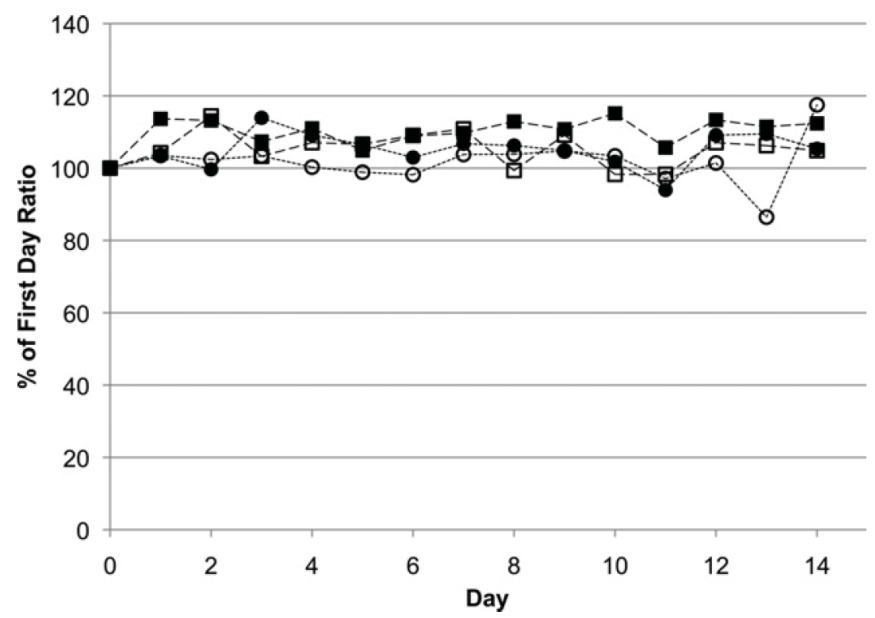


It could be argued that a systematic variation of the concentration in blood should in principle be matched by a similar variation of the isotopically labeled cyanide in aqueous solution (working solution of internal standard in $0.1 \mathrm{~N} \mathrm{NaOH}$ ). The variation of both species in their respective matrices is expected to be the same because they both have the same chemical reactivity. In this case, evaluating stability of cyanide through the ratio of ion 27 to ion 29 would lead to incorrect results. However, since blood is a complex, chemically reactive mixture compared to an aqueous solution, this presumption might be false. The same experiment was performed again, this time assessing the stability of cyanide through the raw area counts for $\mathrm{HCN}$ (ion 27) rather than rationing to the internal standard. Although the variation was found to be larger (163-90\%), no trend (increase or decrease) can be observed. As all four different samples varied in the same way for any given day, the variation seems to be mostly correlated on a daily basis. This indicates a possible instrumental effect, even though care was taken to keep conditions identical. Standard deviation values for areas of ion 27 were below the $15 \%$ limit, which is within the error observed in the reproducibility experiment, keeping in mind that manual injection could lead to large variations.

Another simple test for the stability of cyanide was performed, this time in aqueous solution. The calculated concentration for a stock solution of cyanide that had been prepared 373 days (more than a year) earlier was compared with another one that had been prepared on the same day. The same internal standard stock was used to do the analysis, which allowed a comparison between the calculated concentrations to be made using the t-test. Results showed that the difference in concentration was not statistically significant ( $p=0.61$ ), between fresh and 1 year old aqueous samples (storage at $4{ }^{\circ} \mathrm{C}$ ).

\subsection{1 | Application to forensic cases}

\subsection{1 | Cyanide poisoning}

Only four cases of cyanide poisoning were available for analysis. The results obtained here can be contrasted with cases of non-exposed individuals presented in Section 3.6.2. Additionally, analysis of 9 ante-mortem non-exposed individuals has been performed. No cyanide was detected in 6 of these individuals, and cyanide was in the expected endogenous range for the other three.

In the first case (P.1), a 77 year old man was found dead at home. There was a bottle of potassium cyanide beside him and a small bottle containing an aqueous solution. Quantification using the current method yielded $18 \mu \mathrm{g} / \mathrm{mL}$ for the aqueous solution found at the scene, $21 \mu \mathrm{g} / \mathrm{mL}$ for cardiac blood, $0.3 \mu \mathrm{g} / \mathrm{mL}$ for femoral blood and $33 \mu \mathrm{g} / \mathrm{mL}$ for gastric contents (total volume of $30 \mathrm{~mL}$ ). The high concentrations of the cardiac blood and gastric contents prove the necessity for an extended linear dynamic range for forensic purposes. It is noteworthy that none of the published methods were validated at these elevated concentrations. The phenomenon of post-mortem redistribution may explain the two order of magnitude difference between the cardiac and femoral blood levels however, this has yet to be verified. Although high redistribution ratios have been found in some cyanide cases $^{34}$, the difference in concentrations in the present case is surprising. The route of ingestion might have played a role in the difference in concentrations observed in this case, as well as the one observed in case P.4.

In the second case (P.2), a 58 year old man was found dead in his apartment along with a bottle of potassium cyanide. For this case, only cardiac blood was available and was calculated to have $127 \mu \mathrm{g} / \mathrm{mL}$ cyanide, which was above the validated linear dynamic range. While this result might not be the exact concentration it does not change the forensic interpretation: this was a lethal level of cyanide (i.e. $\gg 1.00 \mu \mathrm{g} / \mathrm{mL}$ ).

In the third case (P.3), a 33 year old man was found on a pedestrian trail. The forensic pathologist noticed a strange smell coming from the gastric contents. For this case, only femoral blood was available. The blood was found to have a concentration of $7.50 \mu \mathrm{g} / \mathrm{mL}$, which was above the lethal level.

In the fourth case (P.4), a 33 year old man was found dead at home. The measured concentrations were $2.4 \mu \mathrm{g} / \mathrm{mL}$ for the cardiac blood, $2.3 \mu \mathrm{g} / \mathrm{mL}$ for the femoral blood and $20.34 \mu \mathrm{g} / \mathrm{mL}$ for the gastric content (total volume of $200 \mathrm{~mL}$ ).

When the results obtained here are compared to those obtained previously using a spectrophotometric method ${ }^{35}$, we observe an agreement in the order of magnitude of the results without the carry over associated with the spectrophotometric method. 
Furthermore the present method has significantly better precision at low concentrations and it can be readily applied to forensic samples.

\subsection{2 | Fires}

Mean blood concentrations of $1.12 \mu \mathrm{g} / \mathrm{mL}$ have been reported in fire cases ${ }^{7}$ but concentrations reported in the literature vary widely. Lindsay et al. ${ }^{2}$ summarized eight blood cyanide concentration studies for fire victims done by various groups. Concentrations found ranged from 0.021 to $9.86 \mu \mathrm{g} / \mathrm{mL}$. Only four studies were done on samples collected at the autopsy, while the other four were done on samples taken at the hospital. None used GC-MS to quantify the cyanide. Most studies had incomplete data, with either no mean, no standard deviation or no range available. Rarely was both femoral and cardiac blood analyzed.

To study the phenomenon of blood cyanide concentration in fire cases, fourteen cases were selected from 2008 to 2010 . When available, both femoral blood and cardiac blood samples were analyzed. The cases selected were house or car fires, where the victim could possibly have inhaled HCN. Results of the analyses are shown in Table 2 .

TABLE 2 Cyanide concentrations found in cardiac and femoral blood samples from fire victims.

\begin{tabular}{lll}
\hline File number & Concentration $(\mu \mathrm{g} / \mathrm{mL})$ & \\
\cline { 2 - 3 } & Cardiac blood & Femoral blood \\
\hline F.1 & ND & 0.32 \\
F. & 0.11 & N/A \\
F.3 & 0.07 & 0.13 \\
F. & 0.11 & 0.94 \\
F.5 & 0.78 & 1.72 \\
F.6 & N/A & 0.44 \\
F.7 & N/A & 0.13 \\
F.8 & Detected & 0.51 \\
F.9 & Detected & 0.27 \\
F.10 & 0.08 & 0.28 \\
F.11 & ND & 0.24 \\
F.12 & ND & Detected \\
F.13 & N/A & 0.23 \\
F.14 & Detected & Detected \\
Mean & 0.23 & 0.47 \\
Standard deviation & $133.9 \%$ & $99.6 \%$ \\
\hline
\end{tabular}

ND: below detection limit $(0.02 \mu \mathrm{g} / \mathrm{mL})$.

Detected: below LOQ $(0.07 \mu \mathrm{g} / \mathrm{mL})$.

As can be seen, mean levels were above the endogenous level, even for smokers $(0.123 \mu \mathrm{g} / \mathrm{mL})$. Moreover, in one case (F.5) the concentration in femoral blood was greater than the toxic level indicating that the death could be attributed to cyanide as opposed to carbon monoxide ( $\mathrm{HbCO}$ was $31 \%$ in this case, while lethal level is 50\%). These results confirm the pertinence of performing cyanide analysis for fire cases.

A surprising phenomenon was observed: the concentrations in femoral blood were greater than the ones in cardiac blood. A paired t-test $(p=0.0122)$ identified the effect as statistically significant at the $95 \%$ confidence level. This phenomenon has never been reported before in the literature. One hypothesis to explain this discrepancy would be the presence of potassium oxalate as a preservative in femoral blood tubes but not in cardiac blood containers. Oxalate could act as a chelator for iron in hemoglobin, thus displacing cyanide and increasing the available concentration of cyanide. Because of the fixed quantity of hemoglobin in 
blood, this effect would be more apparent at low cyanide concentrations than at high concentrations, which would explain why this discrepancy is not observed for poisoning cases.

\section{4 | CONCLUSION}

A method to quantify cyanide in blood, aqueous solutions and gastric contents was developed and validated. This method had a linear dynamic range from 0.07 to $50.00 \mu \mathrm{g} / \mathrm{mL}$ for blood samples with a LOD of $0.02 \mu \mathrm{g} / \mathrm{mL}$. Gastric contents, one of the most variable matrices in forensic toxicology, could be quantified accurately from $1.00 \mu \mathrm{g} / \mathrm{mL}$. The method was built for quantification with $1 \mathrm{~mL}$ of sample but volumes of $0.25 \mathrm{~mL}$ or $0.50 \mathrm{~mL}$ can also be used. Multiple sampling from the headspace can be done without any adverse effect on the quantification up to about 10 injections. Stability of cyanide in blood was evaluated, and the concentration was not found to vary systematically over a two week period for samples stored at $4{ }^{\circ} \mathrm{C}$ or $-20^{\circ} \mathrm{C}$. The method was also successfully applied to forensic cases of cyanide poisoning and fire exposure. The method developed is particularly well adapted to forensic science because of its wide linear range, its adaptability to different biological matrices and its ease and rapidity of use.

\section{References}

1. Calafat AM, Stanfill SB. Rapid quantitation of cyanide in whole blood by automated headspace gas chromatography. Journal of Chromatography B 2002; 772(1): 131-137. doi: 10.1016/S1570-0232(02)00067-3

2. Lindsay AE, Greenbaum AR, O'Hare D. Analytical techniques for cyanide in blood and published blood cyanide concentrations from healthy subjects and fire victims. Analytica Chimica Acta 2004; 511(2): 185-195. doi: 10.1016/j.aca.2004.02.006

3. Berg JM, Tymoczko JL, Stryer L. Biochemistry. New York, United States: W.H. Freeman and Company. 6 ed. 2007.

4. Musshoff F, Kirschbaum KM, Madea B. An uncommon case of a suicide with inhalation of hydrogen cyanide. Forensic Science International 2011; 204(1-3): e4-e7. doi: 10.1016/j.forsciint.2010.05.012

5. Barillo D, Goode R, Rush Jr B, Lin R, Freda A, Anderson Jr E. Lack of correlation between carboxyhemoglobin and cyanide in smoke inhalation injury. Current Surgery 1986; 43(5): 421-423.

6. Dumas P, Gingras G, LeBlanc A. Isotope dilution-mass spectrometry determination of blood cyanide by headspace gas chromatography. Journal of Analytical Toxicology 2005; 29(1): 71-75. doi: 10.1093/jat/29.1.71

7. Baselt RC, Cravey RH. Disposition of Toxic Drugs \& Chemicals in Man. Seal Beach, United States: Biomedical Publications. 4 ed. 1994.

8. Logue BA, Hinkens DM, Baskin SI, Rockwood GA. The analysis of cyanide and its breakdown products in biological samples. Critical Reviews in Analytical Chemistry 2010; 40(2): 122-147. doi: 10.1080/10408340903535315

9. Laforge M, Buneaux F, Houeto P, Bourgeois F, Bourdon R, Levillain P. A rapid spectrophotometric blood cyanide determination applicable to emergency toxicology. Journal of Analytical Toxicology 1994; 18(3): 173-175. doi: 10.1093/jat/18.3.173

10. Lundquist P, Sörbo B. Rapid determination of toxic cyanide concentrations in blood. Clinical Chemistry 1989; 35(4): 617619. doi: 10.1093/clinchem/35.4.617

11. Cruz-Landeira A, Lopez-Rivadulla M, Concheiro-Carro L, Fernandez-Gomez P, Tabernero-Duque M. A new spectrophotometric method for the toxicological diagnosis of cyanide poisoning. Journal of Analytical Toxicology 2000; 24(4): $266-270$. doi: 10.1093/jat/24.4.266

12. Sakayanagi M, Yamada Y, Sakabe C, Watanabe K, Harigaya Y. Identification of inorganic anions by gas chromatography/mass spectrometry. Forensic Science International 2006; 157(2-3): 134-143. doi: 10.1016/j.forsciint.2005.04.003 
13. Felscher D, Wulfmeyer M. A new specific method to detect cyanide in body fluids, especially whole blood, by fluorimetry. Journal of Analytical Toxicology 1998; 22(5): 363-366. doi: 10.1093/jat/22.5.363

14. Chinaka S, Takayama N, Michigami Y, Ueda K. Simultaneous determination of cyanide and thiocyanate in blood by ion chromatography with fluorescence and ultraviolet detection. Journal of Chromatography B: Biomedical Sciences and Applications 1998; 713(2): 353-359. doi: 10.1016/S0378-4347(98)00176-5

15. Saussereau E, Goullé JP, Lacroix C. Determination of thiocyanate in plasma by ion chromatography and ultraviolet detection. Journal of Analytical Toxicology 2007; 31(7): 383-387. doi: 10.1093/jat/31.7.383

16. Odoul M, Fouillet B, Nouri B, Chambon R, Chambon P. Specific determination of cyanide in blood by headspace gas chromatography. Journal of Analytical Toxicology 1994; 18(4): 205-207. doi: 10.1093/jat/18.4.205

17. Zamecnik J, Tam J. Cyanide in blood by gas chromatography with NP detector and acetonitrile as internal standard. Application on air accident fire victims. Journal of Analytical Toxicology 1987; 11(1): 47-48. doi: 10.1093/jat/11.1.47

18. Seto Y, Tsunoda N, Ohta H, Shinohara T. Determination of blood cyanide by headspace gas chromatography with nitrogenphosphorus detection and using a megabore capillary column. Analytica Chimica Acta 1993; 276(2): 247-259. doi: 10.1016/0003-2670(93)80391-W

19. Darr R, Capson T, Hileman F. Determination of hydrogen cyanide in blood using gas chromatography with alkali thermionic detection. Analytical Chemistry 1980; 52(8): 1379-1381. doi: 10.1021/ac50058a058

20. McAuley F, Reive D. Rapid quantitation of cyanide in blood by gas chromatography. Journal of Analytical Toxicology 1983; 7(5): 213-215. doi: 10.1093/jat/7.5.213

21. Cardeal Z, Pradeau D, Hamon M. Determination of HCN by headspace gas chromatography using an improved method of standardisation. Chromatographia 1993; 37(11-12): 613-617. doi: 10.1007/BF02274111

22. Jones A, Löfgren A, Eklund A, Grundin R. Two fatalities from ingestion of acetonitrile: limited specificity of analysis by headspace gas chromatography. Journal of Analytical Toxicology 1992; 16(2): 104-106. doi: 10.1093/jat/16.2.104

23. Ishii A, Seno H, Watanabe-Suzuki K, Suzuki O, Kumazawa T. Determination of cyanide in whole blood by capillary gas chromatography with cryogenic oven trapping. Analytical Chemistry 1998; 70(22): 4873-4876. doi: 10.1021/ac980498b

24. Murphy KE, Schantz MM, Butler TA, Benner Jr BA, Wood LJ, Turk GC. Determination of cyanide in blood by isotope-dilution gas chromatography-mass spectrometry. Clinical Chemistry 2006; 52(3): 458-467. doi: 10.1373/clinchem.2005.061002

25. Seto Y. Oxidative conversion of thiocyanate to cyanide by oxyhemoglobin during acid denaturation. Archives of Biochemistry and Biophysics 1995; 321(1): 245-254. doi: 10.1006/abbi.1995.1392

26. Shibata M, Inoue K, Yoshimura Y, Nakazawa H, Seto Y. Simultaneous determination of hydrogen cyanide and volatile aliphatic nitriles by headspace gas chromatography, and its application to an in vivo study of the metabolism of acrylonitrile in the rat. Archives of Toxicology 2004; 78(6): 301-305. doi: 10.1007/s00204-004-0545-4

27. Takekawa K, Oya M, Kido A, Suzuki O. Analysis of cyanide in blood by headspace solid-phase microextraction (SPME) and capillary gas chromatography. Chromatographia 1998; 47(3-4): 209-214. doi: 10.1007/BF02466583

28. Gambaro V, Arnoldi S, Casagni E, Dell'Acqua L, Pecoraro C, Froldi R. Blood cyanide determination in two cases of fatal intoxication: comparison between headspace gas chromatography and a spectrophotometric method. Journal of Forensic Sciences 2007; 52(6): 1401-1404. doi: 10.1111/j.1556-4029.2007.00570.x

29. Frison G, Zancanaro F, Favretto D, Ferrara SD. An improved method for cyanide determination in blood using solid-phase microextraction and gas chromatography/mass spectrometry. Rapid Communications in Mass Spectrometry 2006; 20(19): 2932-2938. doi: 10.1002/rcm.2689

30. Kolb B, Ettre LS. Static Headspace-Gas Chromatography: Theory and Practice. Hoboken, United States: John Wiley \& Sons. 2 ed. 2006. 
31. Ballantyne B. In vitro production of cyanide in normal human blood and the influence of thiocyanate and storage temperature. Clinical Toxicology 1977; 11(2): 173-193. doi: 10.3109/15563657708989832

32. Pettigrew A, Fell G. Microdiffusion method for estimation of cyanide in whole blood and its application to the study of conversion of cyanide to thiocyanate. Clinical Chemistry 1973; 19(5): 466-471. doi: 10.1093/clinchem/19.5.466

33. Lundquist P, Rosling H, Sörbo B. Determination of cyanide in whole blood, erythrocytes, and plasma. Clinical Chemistry 1985; 31(4): 591-595. doi: 10.1093/clinchem/31.4.591

34. Rhee J, Jung J, Yeom H, et al. Distribution of cyanide in heart blood, peripheral blood and gastric contents in 21 cyanide related fatalities. Forensic Science International 2011;210(1-3): e12-e15. doi: 10.1016/j.forsciint.2011.04.014

35. MA-08-TOX-02, Dosage du Cyanure par Spectrophotométrie,. tech. rep., Laboratoire de sciences judiciaires et de médecine légale; Montréal: 2009.

How to cite this article: B. Desharnais, G. Huppé, M. Lamarche, P. Mireault, and C. D. Skinner (2012), Cyanide quantification in post-mortem biological matrices by headspace GC-MS, Forensic Science International, 222:346-351. 